\title{
Molecular Dynamics Simulation and Kinetic Study of Fluoride Binding to V21C/V66C Myoglobin with a Cytoglobin-like Disulfide Bond
}

\author{
Lu-Lu Yin ${ }^{1}$, Jia-Kun $\mathrm{Xu}^{2}$, Xiao-Juan Wang ${ }^{1}$, Shu-Qin Gao ${ }^{3}$ and Ying-Wu Lin ${ }^{1,3, *}$ \\ 1 School of Chemistry and Chemical Engineering, University of South China, Hengyang 421001, China; \\ yinlulu1625@163.com (L.-L.Y.); wxj0207@126.com (X.-J.W.) \\ 2 Key Lab of Sustainable Development of Polar Fisheries, Ministry of Agriculture and Rural Affairs, Yellow \\ Sea Fisheries Research Institute, Chinese Academy of Fishery Sciences, Lab for Marine Drugs and By \\ products of Pilot National Lab for Marine Science and Technology, Qingdao 266071, China; xujk@ysfri.ac.cn \\ 3 Lab of Protein Structure and Function, University of South China, Hengyang 421001, China; \\ gaoshuqin99@163.com \\ * Correspondence: ywlin@usc.edu.cn; Tel.: +86-743-8578079
}

Received: 21 March 2020; Accepted: 2 April 2020; Published: 4 April 2020

\begin{abstract}
Protein design is able to create artificial proteins with advanced functions, and computer simulation plays a key role in guiding the rational design. In the absence of structural evidence for cytoglobin $(\mathrm{Cgb})$ with an intramolecular disulfide bond, we recently designed a de novo disulfide bond in myoglobin $(\mathrm{Mb})$ based on structural alignment (i.e., V21C/V66C Mb double mutant). To provide deep insight into the regulation role of the Cys21-Cys66 disulfide bond, we herein perform molecular dynamics (MD) simulation of the fluoride-protein complex by using a fluoride ion as a probe, which reveals detailed interactions of the fluoride ion in the heme distal pocket, involving both the distal His64 and water molecules. Moreover, we determined the kinetic parameters of fluoride binding to the double mutant. The results agree with the MD simulation and show that the formation of the Cys21-Cys66 disulfide bond facilitates both fluoride binding to and dissociating from the heme iron. Therefore, the combination of theoretical and experimental studies provides valuable information for understanding the structure and function of heme proteins, as regulated by a disulfide bond. This study is thus able to guide the rational design of artificial proteins with tunable functions in the future.
\end{abstract}

Keywords: heme proteins; protein design; disulfide bond; MD simulation; fluoride ion

\section{Introduction}

Protein design is able to not only reveal the structure-function relationship of native proteins, but also create artificial proteins with advanced functions [1-12]. This is especially the case for heme protein design, which has received much attention in the last few decades, and various approaches have been established for rational design, such as the introduction of non-heme metal ions and unnatural amino acids, and the use of heme mimics to act as an active site [1-12]. Importantly, computer modeling and molecular dynamics (MD) simulation play key roles in guiding the protein design [13-18]. For example, computer simulation was successfully applied to design a non-heme iron binding site in the heme pocket of myoglobin $(\mathrm{Mb})$, which converted an $\mathrm{O}_{2}$ carrier into a functional nitric oxide reductase [19]. With the help of Rosetta matcher, $\mathrm{Lu}$ and co-workers rationally designed a [4Fe-4S] cluster in cytochrome $c$ peroxidase $(\mathrm{CcP})$ that closely mimicked the active site and reproduced the function of native sulfite reductase (SiR) [20]. 
Disulfide bond is a common post-translational modification (PTM) of Cys residues, which play crucial roles in regulating the structure and function of proteins [21,22]. For example, manganese peroxidase $(\mathrm{MnP})$ contains five disulfide bonds, and engineering an additional disulfide bond can further increase its tolerance for heat inactivation $[23,24]$. Disulfide bond has also been shown to regulate the binding of ligands in native heme proteins, as observed for neuroglobin $(\mathrm{Ngb})[25,26]$ and cytoglobin $(\mathrm{Cgb})$ [27-30]. Note that both $\mathrm{Ngb}$ and $\mathrm{Cgb}$ are relatively newly discovered globins, with a bis-His coordinated heme and an intramolecular disulfide bond [26,27]. This is different from the $\mathrm{O}_{2}$ carrier $\mathrm{Mb}$, which has a $\mathrm{H}_{2} \mathrm{O} /$ His coordinated heme in ferric state without a disulfide bond (Figure 1a) [31], although these proteins belong to the same globin family. Based on their amino acid sequences and structural alignments, we engineered an intramolecular disulfide bond in $\mathrm{Mb}$, F46C/M55C Mb [32], and V21C/V66C Mb [33], which closely mimics that in Ngb (Cys46-Cys55) and Cgb (Cys38-Cys83), respectively. Moreover, we solved an X-ray structure of a triple mutant F46S/V21C/V66C Mb (Figure 1b) [33], which confirms the formation of a de novo designed disulfide bond of Cys21-Cys66.

(a)

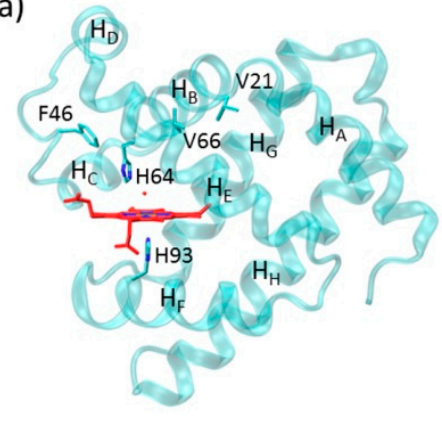

(b)

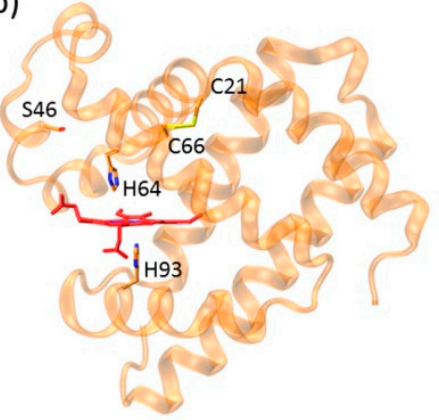

(C)

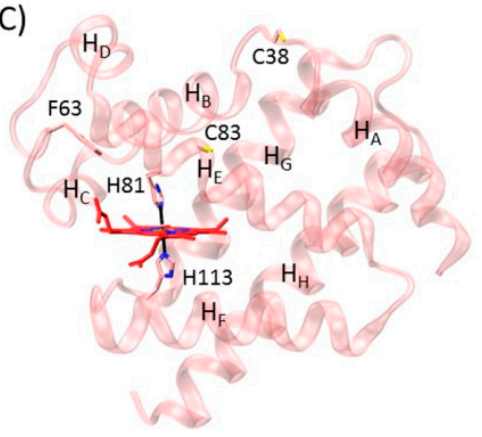

Figure 1. X-ray structure of (a) sperm whale Mb (PDB code 1JP6 [31]), (b) F46S/V21C/V66C Mb mutant (PDB code 5ZEO [33]), and (c) human Cgb (PDB code 1V5H [27]) in their ferric forms. The proximal and distal His residues, the engineered disulfide bond of $\mathrm{C} 21-\mathrm{C} 66$, the reduced residues of $\mathrm{C} 38$ and $\mathrm{C} 83$, and the eight $\alpha$-helices $\left(\mathrm{H}_{\mathrm{A}}-\mathrm{H}_{\mathrm{H}}\right)$ of $\mathrm{Mb}$ and $\mathrm{Cgb}$ are highlighted.

Although the X-ray crystal structure of human $\mathrm{Ngb}$ with an intramolecular disulfide bond was solved previously [26], there is still no 3D structure available for the oxidized form of human Cgb with an intramolecular disulfide bond. Instead, the structure of the reduced form shows that the two sulfur atoms of Cys38 and Cys83 are separated from each other by $12.3 \AA$ (Figure 1c) [27]. Therefore, as a complement, the $\mathrm{X}$-ray crystal structure of $\mathrm{F} 46 \mathrm{~S} / \mathrm{V} 21 \mathrm{C} / \mathrm{V} 66 \mathrm{C} \mathrm{Mb}$ provides valuable information for oxidized $\mathrm{Cgb}$. In a recent study, we confirmed that the formation of an intramolecular disulfide bond enhances the protein stability and fine-tunes protein functions such as nitrite reductase and dehaloperoxidase activities [33].

To further probe the structural-functional consequences of $\mathrm{Mb}$ with a de novo designed disulfide bond of Cys21-Cys66, we herein used a fluoride ion as a probe, as previously applied for various heme proteins [34-39], by performing MD simulation of the fluoride-protein complex. Moreover, to confirm the observation in MD simulation, we determined the kinetic parameters of fluoride binding to the protein. The combination of both theoretical and experimental studies provides valuable information for understanding the structure and function of heme proteins, as regulated by a disulfide bond.

\section{Results and Discussion}

\subsection{Protein Motions of Fluoride-Mb Complexes}

It has been shown that the heme axial water molecule in $\mathrm{Mb}$ (Figure 1a) can be removed upon binding of small exogenous ligands such as a fluoride ion, in turn, the fluoride ion can be used as a probe to study the hydrogen $(\mathrm{H})$-bond interactions in the heme distal site [34-39]. To provide dynamics 
information for $\mathrm{V} 21 \mathrm{C} / \mathrm{V} 66 \mathrm{C} \mathrm{Mb}$ in complex with the fluoride ion, as well as for the fluoride-Wild-type (WT) Mb complex, we performed MD simulations for both protein complexes and monitored the $\mathrm{C} \alpha$ root mean square deviation (RMSD) from the starting structure during $40 \mathrm{~ns}$ of MD simulations. As shown in Figure 2a, the RMSD profile of fluoride-V21C/V66C Mb (red) and fluoride-WT Mb (black) complexes fluctuates around $1 \AA$ after $\sim 10 \mathrm{~ns}$ and $\sim 20 \mathrm{~ns}$, respectively. This observation indicates that the fluoride-V21C/V66C Mb complex first achieves a stable equilibration of the overall structure compared with that of the fluoride-Mb complex, likely due to the stabilization effect of Cys21-Cys66 disulfide bond.

(a)

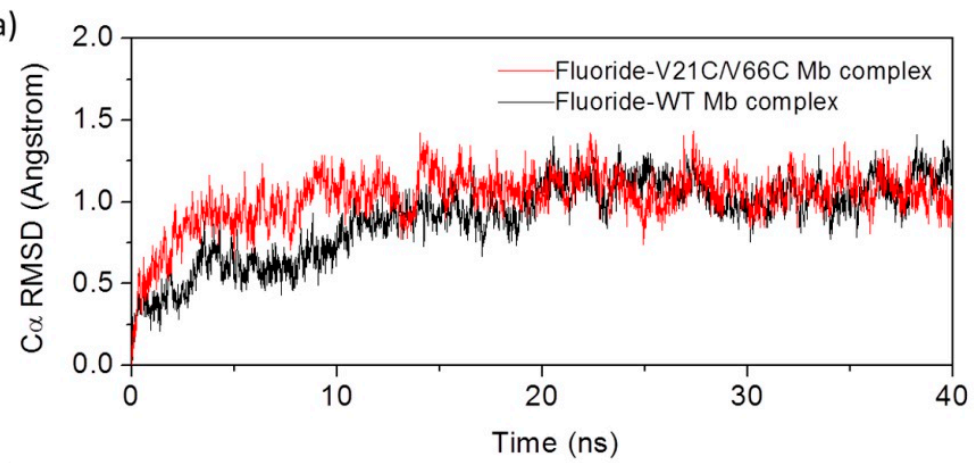

(b)

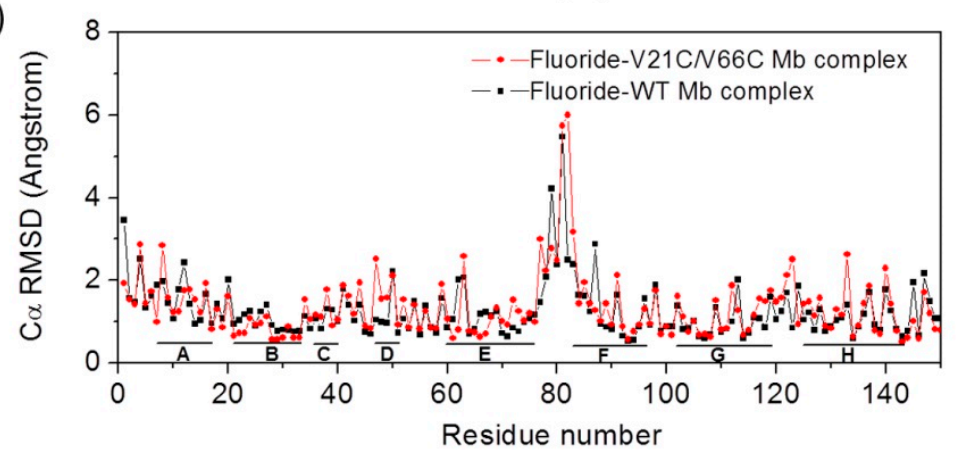

Figure 2. (a) Root mean square deviation (RMSD) for fluoride binding to $\mathrm{WT} \mathrm{Mb}$ and $\mathrm{V} 21 \mathrm{C} / \mathrm{V} 66 \mathrm{C} \mathrm{Mb}$ from the starting structure as a function of time; (b) the average RMSD of each residue for the last $20 \mathrm{~ns}$. The eight $\alpha$-helices $\left(\mathrm{H}_{\mathrm{A}}-\mathrm{H}_{\mathrm{H}}\right)$ are indicated by short solid lines at the bottom.

To provide more detailed information for protein motions, we analyzed the average RMSD over time of each residue for the last $20 \mathrm{~ns}$ (Figure 2b). The results show that the eight $\alpha$-helices in both protein complexes exhibit small deviations around $1 \AA$, with large deviations observed for the loop regions, especially for the loop of $\mathrm{H}_{\mathrm{E}}-\mathrm{H}_{\mathrm{F}}$ (residues 75-81), which agrees well with previous MD studies of $\mathrm{Mb}$ [40]. It was interesting to observe that most residues in the $\mathrm{H}_{\mathrm{B}}$ helix where Cys21 is located exhibit small deviations compared to those in $\mathrm{WT} \mathrm{Mb}$, and similar situations were observed for most residues in $\mathrm{H}_{\mathrm{E}}$ where Cys66 is located. These observations suggest that the formation of Cys21-Cys66 disulfide bond enhances the protein stability for the local region, without alteration of the overall protein motions.

\subsection{Structural Comparison of Fluoride $-M b$ Complexes}

With energy minimization and equilibration, the simulated overall structure of the two fluoride-Mb complexes is similar. To make a detailed structural comparison, we overlapped the two structures according to the heme iron center. As shown in Figure 3, the spatial orientations of $\alpha$-helices $\mathrm{H}_{\mathrm{A}}-\mathrm{H}_{\mathrm{E}}$ are slightly different between these two complexes, whereas those of the last three $\alpha$-helices $\mathrm{H}_{\mathrm{F}}-\mathrm{H}_{\mathrm{H}}$ are very similar to each other. With the formation of Cys21-Cys66 disulfide bond, the loop between $\mathrm{H}_{\mathrm{A}}$ and $\mathrm{H}_{\mathrm{B}}$ where Cys21 is located shifted toward the middle of $\mathrm{H}_{\mathrm{E}}$ where Cys66 is located, which induced a locally structural rearrangement. As a result, both $\mathrm{H}_{\mathrm{C}}$ and $\mathrm{H}_{\mathrm{D}}$, including the long loop 
connecting, underwent a structural rearrangement. Note that the introduction of a de novo disulfide of Cys46-Cys55 in this region mimicking that in native human Ngb regulates the protein structure and enhances the peroxidase activity [32]. These results also agree with the structural comparison between $\mathrm{WT} \mathrm{Mb}$ and F46S/V21C/V66C Mb triple mutant in their X-ray crystal structures [33], albeit with more protein motions in MD simulations due to in the solution state.

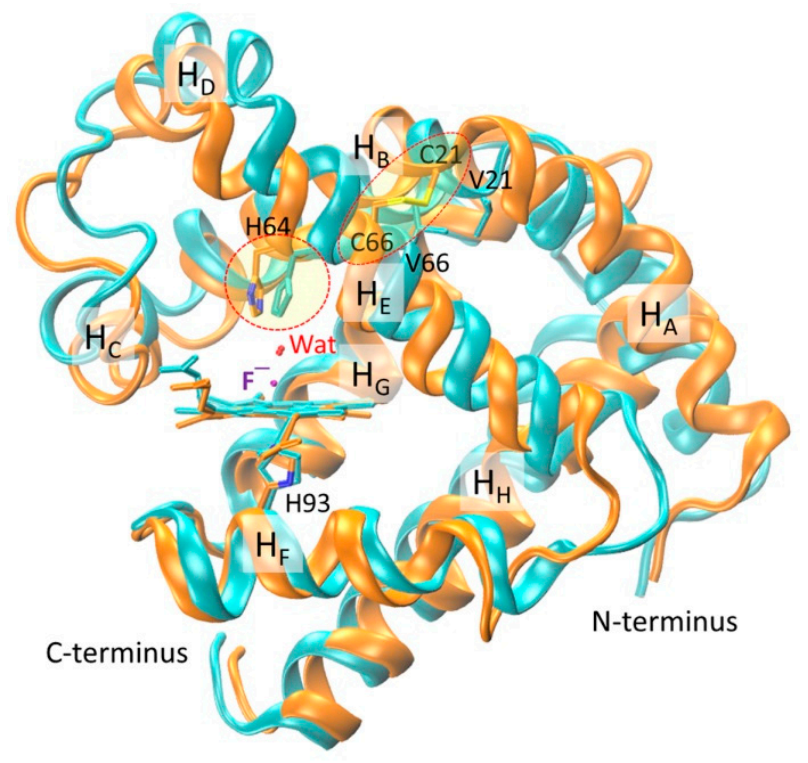

Figure 3. Overlap of modeling structures of fluoride-WT Mb (cyan) and fluoride-V21C/V66C Mb (orange) complexes. The heme group, proximal His93, axial fluoride ion, distal water, $\mathrm{N}$ - and C-terminus, and eight $\alpha$-helices $\left(\mathrm{H}_{\mathrm{A}}-\mathrm{H}_{\mathrm{H}}\right)$ are highlighted for clarifications. The conformation of distal His64 and the disulfide bond of $\mathrm{C} 21-\mathrm{C} 66$ are indicated by dashed circles.

Moreover, as a consequence of structural rearrangement, the spatial orientation of heme distal His64 is different in the two protein complexes (indicated by a circle line in Figure 3), although the heme axial fluoride ions, as well as the distal water molecules, overlapped very well. This observation suggests that the formation of an intramolecular disulfide bond can regulate the conformation of heme distal histidine, thereby fine-tuning the ligand binding property and protein reactivity, as those observed for native $\mathrm{Cgb}$ with a bis-His heme coordination [27-30].

\subsection{Interactions of Fluoride ion with Mbs}

To provide detailed information for the heme active site of the fluoride-Mb complexes, we monitored the distance between the heme axial fluoride ion and the distal His64 $(\mathrm{N} \varepsilon$ atom) during the last $20 \mathrm{~ns}$ in MD simulation. Moreover, the heme distal water molecule in the equilibrated structure at the end of simulation was also monitored for the last $20 \mathrm{~ns}$. As shown in Figure 4a for the fluoride-WT $\mathrm{Mb}$ complex, upon fluoride binding to the heme iron, the distance between the fluoride ion and the $\mathrm{N} \varepsilon$ atom of distal His 64 was $\sim 4.1 \AA$ for the last 20 ns. Note that the distance of Fe-F coordination bond was found to be $\sim 1.8 \AA$, the same value as optimized in a previous study by Smulevich and co-workers [37]. The heme distal water molecule in the equilibrated structure (Figure $4 \mathrm{~b}$ ) acted as a bridge by forming two H-bonds with a fluoride ion and the distal His64, simultaneously. Moreover, it was interesting to observe that the distal water molecule underwent large distance changes in simulation. By inspecting the MD trajectory, we noted that this was attributed to the existence of several water molecules that may also form H-bond interactions with the fluoride ion and stabilize its coordination. This phenomenon was also observed for fluoride binding to Thermobifida fusca hemoglobin in previous MD simulation [37]. 
(a)

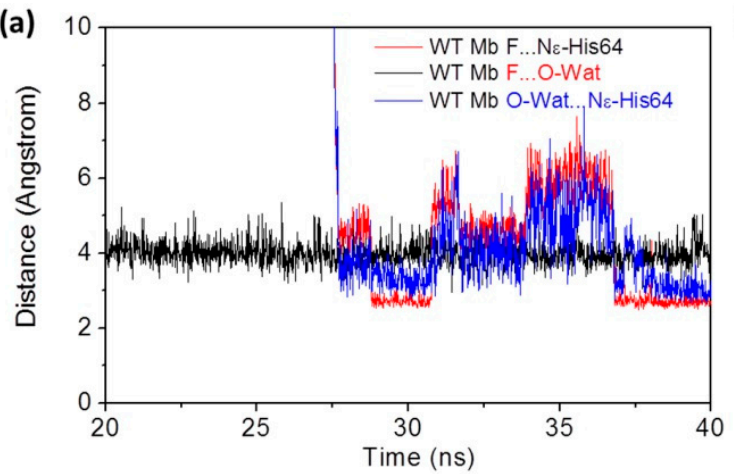

(c)

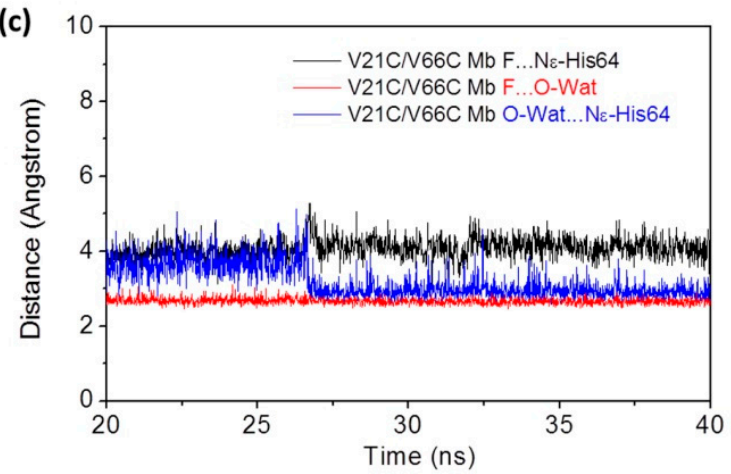

(b)

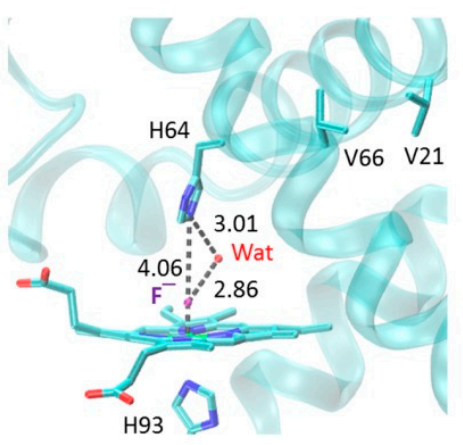

(d)

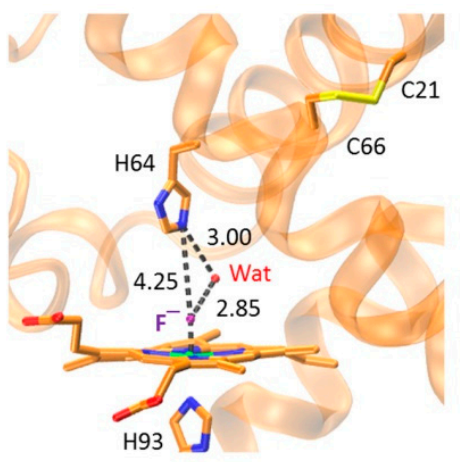

Figure 4. Time-dependence of distances between fluoride ion and the distal His64, fluoride ion and distal water, and distal water and His64, for $\mathrm{WT} \mathrm{Mb} \mathrm{(a)} \mathrm{and} \mathrm{V21C/V66C} \mathrm{Mb} \mathrm{(c),} \mathrm{respectively.} \mathrm{The}$ modeling structures of $\mathrm{WT} \mathrm{Mb}(\mathbf{b})$ and $\mathrm{V} 21 \mathrm{C} / \mathrm{V} 66 \mathrm{C} \mathrm{Mb}(\mathbf{d})$ at the end of simulation. The H-bond interactions in the heme distal site are indicated by dotted lines, as well as the distance $(\AA)$.

In case of the fluoride-V21C/V66C Mb complex (Figure 4c,d), it was found that the heme distal His64 has a slightly large distance to the axial fluoride ion $(\sim 4.3 \AA)$. Similarly, a distal water molecule interacted with both the distal His64 and the fluoride ion, by forming an H-bonding network. Although several water molecules were also observed in the MD trajectory, the H-bond distances of the distal water did not change dramatically, especially for the last $12 \mathrm{~ns}$. Note that multiple water molecules were also observed in the X-ray structure of $\mathrm{Mb}$ with a modified heme center, such as in $\mathrm{L} 29 \mathrm{E} \mathrm{Mb}$ mutant containing three water molecules, which was found to regulate ligand binding including the fluoride ion, as well as protein reactivity such as $\mathrm{H}_{2} \mathrm{O}_{2}$ activation [41]. These observations suggest that with the formation of the Cys21-Cys66 disulfide bond and structural rearrangement, the fluoride ion may exhibit a different binding property to the heme iron compared to that binding to $\mathrm{WT} \mathrm{Mb}$.

\subsection{Kinetic Binding of Fluoride ion to Mbs}

With the theoretical information from MD simulation, we were also interested in determining the kinetic parameters for fluoride binding to the protein using the experimental method. For this purpose, we performed stopped-flow UV-Vis spectroscopic studies for fluoride binding to V21C/V66C $\mathrm{Mb}$, with $\mathrm{WT} \mathrm{Mb}$ as a control. As shown in Figure 5a, the spectra showed that the Soret band rapidly shifted from $409 \mathrm{~nm}$ to $407 \mathrm{~nm}$ upon mixing V21C/V66C Mb with the fluoride ion, with a decrease of $504 \mathrm{~nm}$ in absorption and concomitant increase of a charge-transfer (CT1) band at $604 \mathrm{~nm}$, similar to that observed for fluoride binding to a dehaloperoxidase (DHP) $(605 \mathrm{~nm})$ [42]. The resultant new spectrum ( $407 \mathrm{~nm}$ and $604 \mathrm{~nm}$ ) resembles that of the fluoride-WT Mb complex (406 nm and $607 \mathrm{~nm}$ ), as reported in a previous study [38]. Moreover, as shown in Figure 5a (inset), the absorbance change of the Soret band was fitted well to a single exponential decay equation, indicating the rapid formation of a stable fluoride-protein complex within $5 \mathrm{~s}$. 
(a)

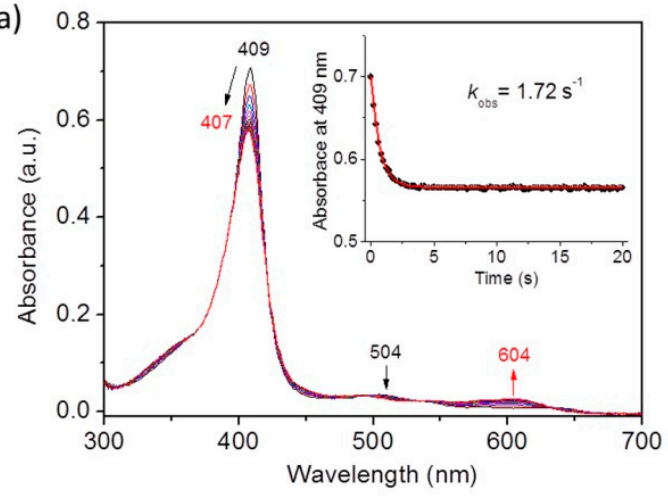

(b)

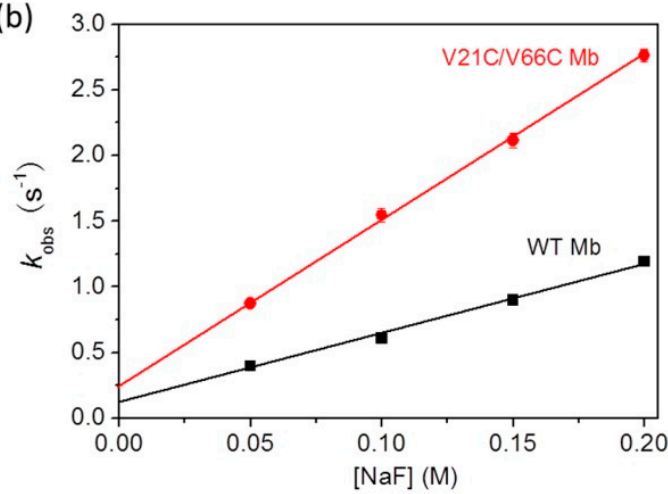

Figure 5. (a) Stopped-flow spectra upon mixing V21C/V66C Mb and fluoride (5 $\mu \mathrm{M}$ and $100 \mathrm{mM}$, respectively, final concentration) in $100 \mathrm{mM} \mathrm{KH_{2 }} \mathrm{PO}_{4}$ buffer ( $\mathrm{pH}$ 7.0) for $20 \mathrm{~s}$. (b) Plots of observed rate constants versus fluoride concentrations, with $\mathrm{WT} \mathrm{Mb} \mathrm{shown} \mathrm{for} \mathrm{comparison.}$

To obtain the kinetic parameters, we analyzed the results by plotting the rate constants $\left(k_{\mathrm{obs}}\right)$ versus fluoride concentrations (Figure $5 \mathrm{~b}$ ). The obtained association rate constant, $k_{\mathrm{a}}\left(k_{\mathrm{on}}\right)$, and the dissociation rate constant, $k_{\mathrm{d}}\left(k_{\text {off }}\right)$, are summarized in Table 1 . Note that the $k_{\text {on }}$ and $k_{\text {off }}$ values determined for WT Mb are similar to those reported for horse $\mathrm{Mb}\left(6.0 \pm 0.5 \mathrm{M}^{-1} \mathrm{~s}^{-1}\right.$ and $\left.0.10 \pm 0.01 \mathrm{~s}^{-1}\right)$ under similar conditions [36]. The results showed that V21C/V66C Mb exhibited a fluoride binding rate constant $\left(k_{\mathrm{on}}\right) \sim 2.4$-fold higher than that of $\mathrm{WT} \mathrm{Mb}$. At the same time, it exhibited a doubly increased dissociation rate constant $\left(k_{\mathrm{on}}\right)$. As a result, $\mathrm{V} 21 \mathrm{C} / \mathrm{V} 66 \mathrm{C} \mathrm{Mb}$ showed a slightly enhanced equilibrium for fluoride binding $\left(k_{\mathrm{on}} / k_{\mathrm{off}}\right)$ compared to that of WT Mb (Table 1$)$. These results suggest that the conformational change of distal His64 upon formation of the Cys21-Cys66 disulfide bond leads to rapid fluoride binding, as well as rapid dissociation from the heme iron, presumably due to the weakened interactions with distal His64 and water molecules. These results also indicate that the de novo designed disulfide bond of Cys21-Cys66 in Mb plays a fine-tuning role resembling that in $\mathrm{Cgb}$, where Cys38-Cys83 was shown to play a key role in tuning the binding affinity of exogenous ligands by changing the oxidation/reduction state of the disulfide bond [43,44].

Table 1. Comparison of the kinetic parameters of fluoride binding to WT Mb and the double mutant of $\mathrm{V} 21 \mathrm{C} / \mathrm{V} 66 \mathrm{C} \mathrm{Mb}$ with an intramolecular disulfide bond.

\begin{tabular}{lccc}
\hline Proteins & $\boldsymbol{k}_{\text {on }}\left(\mathbf{M}^{\mathbf{- 1}} \mathbf{s}^{-\mathbf{1}}\right)$ & $\boldsymbol{k}_{\text {off }}\left(\mathbf{s}^{-\mathbf{1}}\right)$ & $\boldsymbol{k}_{\text {on }} / \boldsymbol{k}_{\text {off }}\left(\mathbf{M}^{-\mathbf{1}}\right)$ \\
\hline $\mathrm{WT} \mathrm{Mb}$ & $5.14 \pm 0.15$ & $0.13 \pm 0.01$ & 39.5 \\
$\mathrm{~V} 21 \mathrm{C} / \mathrm{V} 66 \mathrm{C} \mathrm{Mb}$ & $12.48 \pm 0.26$ & $0.27 \pm 0.04$ & 46.2 \\
\hline
\end{tabular}

\section{Conclusions}

In summary, we performed MD simulation of fluoride-V21C/V66C Mb complex with a de novo designed disulfide bond of Cys21-Cys66 mimicking that in human $\mathrm{Cgb}$, with the fluoride-WT Mb complex as a control. The results show that the formation of Cys21-Cys66 disulfide bond in $\mathrm{Mb}$ enhances the protein stability for the local region and alters the conformation of heme distal His64. As a consequence, the fluoride ion interacts differently with the distal His64, as well as the water molecules in the heme distal pocket, compared to that in WT Mb. Kinetic study of fluoride binding to the protein further revealed that the micro-environmental changes in the heme active site enhance the rate of fluoride binding, as well as its dissociation from the heme iron. These observations indicate that the disulfide bond of Cys21-Cys66 in V21C/V66C Mb double mutant plays crucial roles in regulating both protein stability and ligand binding property, resembling the roles of Cys38-Cys83 in native Cgb. Therefore, the combination of both theoretical and experimental studies provides valuable information for understanding the structure and function of heme proteins, as regulated by a disulfide bond. 
Moreover, with the fine-tuning role of an intramolecular disulfide bond, this study is able to guide the rational design of artificial proteins with tunable functions in the future.

\section{Materials and Methods}

\subsection{Materials and Reagents}

Wild-type sperm whale $\mathrm{Mb}$ was expressed using the $\mathrm{Mb}$ gene of $\mathrm{pMbt7-7}$ and purified using the procedure described previously [28]. V21C/V66C Mb mutant was prepared as reported in our previous study [33]. $\mathrm{KH}_{2} \mathrm{PO}_{4}, \mathrm{NaF}$, and other chemicals were commercial products and of analytic grade. Deionized water was used throughout the experiments.

\subsection{Molecular Dynamics Studies}

The initial structure of $\mathrm{V} 21 \mathrm{C} / \mathrm{V} 66 \mathrm{C} \mathrm{Mb}$ was constructed based on the X-ray crystal structure of WT $\mathrm{Mb}$ (PDB code 1JP6 [31]) using program VMD 1.9. The heme axial water molecule in the $X$-ray structure was replaced by a fluoride ion for simulation of the fluoride-Mb complex. A patch of disulfide bond was applied to Cys21 and Cys66 for simulation of V21C/V66C Mb with an intramolecular disulfide bond. The protein was then solvated in a cubic box of TIP3 water, which extended $10 \AA$ away from any given protein atom. Counter ions $\left(\mathrm{Na}^{+}\right.$and $\left.\mathrm{Cl}^{-}\right)$were further added to obtain the physiological ionic strength of $0.15 \mathrm{M}$ by using the autoionize plug-in of VMD 1.9 [45]. The resulting system was minimized with NAMD2.9 (Nanoscale Molecular Dynamics) [46] using 50,000 minimization steps with conjugate gradient method at $0 \mathrm{~K}$, and equilibrated for 40,000,000 molecular dynamics steps (1 fs per step, $40 \mathrm{~ns}$ in total) at $300 \mathrm{~K}$, then further minimized for 50,000 steps at $0 \mathrm{~K}$. The trajectory data were saved every 10,000 steps, and control simulation of fluoride binding to $\mathrm{WT} \mathrm{Mb}$ was performed under the same conditions. Visualization and data analysis were done with VMD 1.9.

\subsection{UV-Vis Kinetic Studies}

UV-Vis spectra were recorded in $100 \mathrm{mM} \mathrm{KH}_{2} \mathrm{PO}_{4}$ (pH 7.0) on a Hewlett-Packard 8453 diode array spectrometer. Protein concentration was determined with an extinction coefficient of $\varepsilon_{409}=157$ $\mathrm{mM}^{-1} \cdot \mathrm{cm}^{-1}$ for WT Mb [47]; $\varepsilon_{409}=150 \pm 5 \mathrm{mM}^{-1} \cdot \mathrm{cm}^{-1}$ for F46C/M55C Mb [33]. Fluoride binding to the heme center of WT Mb and F46C/M55C Mb was carried out with a SF-61DX2 Hi-Tech KinetAsyst ${ }^{\mathrm{TM}}$ dual mixing stopped-flow spectrophotometer. The binding kinetics was measured by mixing the protein $\left(10 \mu \mathrm{M}\right.$ in $100 \mathrm{mM} \mathrm{KH}_{2} \mathrm{PO}_{4}$ buffer, $\mathrm{pH}$ 7.0) in one syringe with increasing concentrations of $\mathrm{NaF}$ $(0.1-0.4 \mathrm{M})$ in the second syringe, with an equal volume of solutions. The observed rate constant $\left(k_{\mathrm{obs}}\right)$ was obtained by fitting the change of the protein Soret band to the mono-exponential decay equation. The association rate constant, $k_{\mathrm{a}}\left(k_{\mathrm{on}}\right)$, and the dissociation rate constant, $k_{\mathrm{d}}\left(k_{\text {off }}\right)$, were determined from a plot of $k_{\mathrm{obs}}$ versus the fluoride concentration (i.e., $k_{\mathrm{obs}}=k_{\mathrm{on}}\left[\mathrm{F}^{-}\right]+k_{\mathrm{off}}$ ), where the slope and intercept correspond to $k_{\text {on }}$ and $k_{\text {off }}$, respectively.

Author Contributions: Y.-W.L. designed the project. L.-L.Y., J.-K.X., X.-J.W., and S.-Q.G. performed the experiments and analyzed the data. Y.-W.L. wrote the manuscript. All authors have read and agreed to the published version of the manuscript.

Funding: This work was supported by the National Natural Science Foundation of China (21977042, 31200642, 21807058) and the Open Project Fund of Key Laboratory of Sustainable Development of Polar Fishery, Ministry of Agriculture and Rural Affairs of PRC (No. 2019OPF01).

Acknowledgments: It is a pleasure to acknowledge S.G. Sligar and Y. Lu of the University of Illinois at Urbana-Champaign, for the kind gift of sperm whale Mb gene. NAMD and VMD were developed by the Theoretical Biophysics Group in the Beckman Institute for Advanced Science and Technology at the University of Illinois at Urbana-Champaign.

Conflicts of Interest: The authors declare no conflict of interest. 


\section{References}

1. Lu, Y.; Yeung, N.; Sieracki, N.; Marshall, N.M. Design of functional metalloproteins. Nature 2009, 460, 855-862. [CrossRef] [PubMed]

2. Lin, Y.-W. Rational design of metalloenzymes: From single to multiple active sites. Coord. Chem. Rev. 2017, 336, 1-27. [CrossRef]

3. Hirota, S.; Lin, Y.-W. Design of artificial metalloproteins/metalloenzymes by tuning noncovalent interactions. J. Biol. Inorg. Chem. 2018, 23, 7-25. [CrossRef] [PubMed]

4. Schwizer, F.; Okamoto, Y.; Heinisch, T.; Gu, Y.; Pellizzoni, M.M.; Lebrun, V.; Reuter, R.; Kohler, V.; Lewis, J.C.; Ward, T.R. Artificial Metalloenzymes: Reaction Scope and Optimization Strategies. Chem. Rev. 2018, 118, 142-231. [CrossRef]

5. Yu, Y.; Hu, C.; Xia, L.; Wang, J. Artificial Metalloenzyme Design with Unnatural Amino Acids and Non-Native Cofactors. ACS Catal. 2018, 8, 1851-1863. [CrossRef]

6. Mirts, E.N.; Bhagi-Damodaran, A.; Lu, Y. Understanding and Modulating Metalloenzymes with Unnatural Amino Acids, Non-Native Metal Ions, and Non-Native Metallocofactors. Acc. Chem. Res. 2019, 52, 935-944. [CrossRef]

7. Oohora, K.; Onoda, A.; Hayashi, T. Hemoproteins Reconstituted with Artificial Metal Complexes as Biohybrid Catalysts. Acc. Chem. Res. 2019, 52, 945-954. [CrossRef]

8. Shoji, O.; Aiba, Y.; Watanabe, Y. Hoodwinking Cytochrome P450BM3 into Hydroxylating Non-Native Substrates by Exploiting Its Substrate Misrecognition. Acc. Chem. Res. 2019, 52, 925-934. [CrossRef]

9. Nastri, F.; D’Alonzo, D.; Leone, L.; Zambrano, G.; Pavone, V.; Lombardi, A. Engineering Metalloprotein Functions in Designed and Native Scaffolds. Trends Biochem. Sci. 2019, 44, 1022-1040. [CrossRef]

10. Xu, J.; Wang, C.; Cong, Z. Strategies for Substrate-Regulated P450 Catalysis: From Substrate Engineering to Co-Catalysis. Chemistry 2019, 25, 6853-6863. [CrossRef]

11. Lin, Y.-W. Rational Design of Artificial Metalloproteins and Metalloenzymes with Metal Clusters. Molecules 2019, 24, 2743. [CrossRef] [PubMed]

12. Lin, Y.-W. Rational design of heme enzymes for biodegradation of pollutants toward a green future. Biotechnol. Appl. Biochem. 2020. [CrossRef] [PubMed]

13. Nanda, V.; Koder, R.L. Designing artificial enzymes by intuition and computation. Nat. Chem. 2010, $2,15-24$. [CrossRef]

14. Lin, Y.-W. Structural insights into a low-spin myoglobin variant with bis-histidine coordination from molecular modeling. Proteins 2011, 79, 679-684. [CrossRef] [PubMed]

15. Lin, Y.-W.; Nie, C.M.; Liao, L.F. Rational design of a nitrite reductase based on myoglobin: A molecular modeling and dynamics simulation study. J. Mol. Model. 2012, 18, 4409-4415. [CrossRef]

16. Lin, Y.-W.; Shu, X.-G.; Du, K.-J.; Nie, C.-M.; Wen, G.-B. Computational insight into nitration of human myoglobin. Comput. Biol. Chem. 2014, 52, 60-65. [CrossRef]

17. Muñoz Robles, V.; Ortega-Carrasco, E.; Alonso-Cotchico, L.; Rodriguez-Guerra, J.; Lledós, A.; Maréchal, J.-D. Toward the Computational Design of Artificial Metalloenzymes: From Protein-Ligand Docking to Multiscale Approaches. ACS Catal. 2015, 5, 2469-2480. [CrossRef]

18. Moore, E.J.; Zorine, D.; Hansen, W.A.; Khare, S.D.; Fasan, R. Enzyme stabilization via computationally guided protein stapling. Proc. Natl. Acad. Sci. USA 2017, 114, 12472-12477. [CrossRef]

19. Yeung, N.; Lin, Y.-W.; Gao, Y.-G.; Zhao, X.; Russell, B.S.; Lei, L.; Miner, K.D.; Robinson, H.; Lu, Y. Rational design of a structural and functional nitric oxide reductase. Nature 2009, 462, 1079-1082. [CrossRef]

20. Mirts, E.N.; Petrik, I.D.; Hosseinzadeh, P.; Nilges, M.J.; Lu, Y. A designed heme-[4Fe-4S] metalloenzyme catalyzes sulfite reduction like the native enzyme. Science 2018, 361, 1098-1101. [CrossRef]

21. Chalker, J.M.; Bernardes, G.J.; Lin, Y.A.; Davis, B.G. Chemical modification of proteins at cysteine: Opportunities in chemistry and biology. Chem. Asian J. 2009, 4, 630-640. [CrossRef] [PubMed]

22. Lin, Y.-W. Structure and function of heme proteins regulated by diverse post-translational modifications. Arch. Biochem. Biophys. 2018, 641, 1-30. [CrossRef] [PubMed]

23. Reading, N.S.; Aust, S.D. Engineering a disulfide bond in recombinant manganese peroxidase results in increased thermostability. Biotechnol. Prog. 2000, 16, 326-333. [CrossRef] [PubMed]

24. Reading, N.S.; Aust, S.D. Role of disulfide bonds in the stability of recombinant manganese peroxidase. Biochemistry 2001, 40, 8161-8168. [CrossRef] 
25. Tiso, M.; Tejero, J.; Basu, S.; Azarov, I.; Wang, X.; Simplaceanu, V.; Frizzell, S.; Jayaraman, T.; Geary, L.; Shapiro, C.; et al. Human neuroglobin functions as a redox-regulated nitrite reductase. J. Biol. Chem. 2011, 286, 18277-18289. [CrossRef]

26. Guimaraes, B.G.; Hamdane, D.; Lechauve, C.; Marden, M.C.; Golinelli-Pimpaneau, B. The crystal structure of wild-type human brain neuroglobin reveals flexibility of the disulfide bond that regulates oxygen affinity. Acta Crystallogr. D Biol. Crystallogr. 2014, 70, 1005-1014. [CrossRef]

27. Sugimoto, H.; Makino, M.; Sawai, H.; Kawada, N.; Yoshizato, K.; Shiro, Y. Structural basis of human cytoglobin for ligand binding. J. Mol. Biol. 2004, 339, 873-885. [CrossRef]

28. Astudillo, L.; Bernad, S.; Derrien, V.; Sebban, P.; Miksovska, J. Reduction of the internal disulfide bond between Cys 38 and 83 switches the ligand migration pathway in cytoglobin. J. Inorg. Biochem. 2013, 129, 23-29. [CrossRef]

29. Beckerson, P.; Reeder, B.J.; Wilson, M.T. Coupling of disulfide bond and distal histidine dissociation in human ferrous cytoglobin regulates ligand binding. FEBS Lett. 2015, 589, 507-512. [CrossRef]

30. Reeder, B.J.; Ukeri, J. Strong modulation of nitrite reductase activity of cytoglobin by disulfide bond oxidation: Implications for nitric oxide homeostasis. Nitric Oxide 2018, 72, 16-23. [CrossRef]

31. Urayama, P.; Phillips Jr, G.N.; Gruner, S.M. Probing substates in sperm whale myoglobin using high-pressure crystallography. Structure 2002, 10, 51-60. [CrossRef]

32. Wu, L.-B.; Yuan, H.; Zhou, H.; Gao, S.-Q.; Nie, C.-M.; Tan, X.; Wen, G.-B.; Lin, Y.-W. An intramolecular disulfide bond designed in myoglobin fine-tunes both protein structure and peroxidase activity. Arch. Biochem. Biophys. 2016, 600, 47-55. [CrossRef] [PubMed]

33. Yin, L.-L.; Yuan, H.; Du, K.-J.; He, B.; Gao, S.-Q.; Wen, G.-B.; Tan, X.; Lin, Y.-W. Regulation of both the structure and function by a de novo designed disulfide bond: A case study of heme proteins in myoglobin. Chem. Commun. (Camb.) 2018, 54, 4356-4359. [CrossRef] [PubMed]

34. Aime, S.; Fasano, M.; Paoletti, S.; Cutruzzola, F.; Desideri, A.; Bolognesi, M.; Rizzi, M.; Ascenzi, P. Structural determinants of fluoride and formate binding to hemoglobin and myoglobin: Crystallographic and $1 \mathrm{H}-\mathrm{NMR}$ relaxometric study. Biophys. J. 1996, 70, 482-488. [CrossRef]

35. Neri, F.; Kok, D.; Miller, M.A.; Smulevich, G. Fluoride binding in hemoproteins: The importance of the distal cavity structure. Biochemistry 1997, 36, 8947-8953. [CrossRef]

36. Merryweather, J.; Summers, F.; Vitello, L.B.; Erman, J.E. Metmyoglobin/fluoride: Effect of distal histidine protonation on the association and dissociation rate constants. Arch. Biochem. Biophys. 1998, 358, 359-368. [CrossRef]

37. Nicoletti, F.P.; Droghetti, E.; Boechi, L.; Bonamore, A.; Sciamanna, N.; Estrin, D.A.; Feis, A.; Boffi, A.; Smulevich, G. Fluoride as a probe for H-bonding interactions in the active site of heme proteins: The case of Thermobifida fusca hemoglobin. J. Am. Chem. Soc. 2011, 133, 20970-20980. [CrossRef]

38. Droghetti, E.; Nicoletti, F.P.; Bonamore, A.; Sciamanna, N.; Boffi, A.; Feis, A.; Smulevich, G. The optical spectra of fluoride complexes can effectively probe H-bonding interactions in the distal cavity of heme proteins. J. Inorg. Biochem. 2011, 105, 1338-1343. [CrossRef]

39. Kosowicz, J.G.; Boon, E.M. Insights into the distal heme pocket of H-NOX using fluoride as a probe for H-bonding interactions. J. Inorg. Biochem. 2013, 126, 91-95. [CrossRef]

40. Bossa, C.; Amadei, A.; Daidone, I.; Anselmi, M.; Vallone, B.; Brunori, M.; Di Nola, A. Molecular dynamics simulation of sperm whale myoglobin: Effects of mutations and trapped $\mathrm{CO}$ on the structure and dynamics of cavities. Biophys. J. 2005, 89, 465-474. [CrossRef]

41. Du, J.-F.; Li, W.; Li, L.; Wen, G.-B.; Lin, Y.-W.; Tan, X. Regulating the coordination state of a heme protein by a designed distal hydrogen-bonding network. ChemistryOpen 2015, 4, 97-101. [CrossRef] [PubMed]

42. Nicoletti, F.P.; Thompson, M.K.; Howes, B.D.; Franzen, S.; Smulevich, G. New Insights into the Role of Distal Histidine Flexibility in Ligand Stabilization of Dehaloperoxidase-Hemoglobin from Amphitrite ornata. Biochemistry 2010, 49, 1903-1912. [CrossRef] [PubMed]

43. Hamdane, D.; Kiger, L.; Dewilde, S.; Green, B.N.; Pesce, A.; Uzan, J.; Burmester, T.; Hankeln, T.; Bolognesi, M.; Moens, L.; et al. Coupling of the heme and an internal disulfide bond in human neuroglobin. Micron 2004, 35, 59-62. [CrossRef] [PubMed]

44. Sturms, R.; DiSpirito, A.A.; Fulton, D.B.; Hargrove, M.S. Hydroxylamine Reduction to Ammonium by Plant and Cyanobacterial Hemoglobins. Biochemistry 2011, 50, 10829-10835. [CrossRef] 
45. Humphrey, W.; Dalke, A.; Schulten, K. VMD: Visual molecular dynamics. J. Mol. Graph. 1996, 14, $33-38$. [CrossRef]

46. Kalé, L.; Skeel, R.; Bhandarkar, M.; Brunner, R.; Gursoy, A.; Krawetz, N.; Phillips, J.; Shinozaki, A.; Varadarajan, K.; Schulten, K. NAMD2: Greater Scalability for Parallel Molecular Dynamics. J. Comput. Phys. 1999, 151, 283-312. [CrossRef]

47. Springer, B.A.; Sligar, S.G. High-level expression of sperm whale myoglobin in Escherichia coli. Proc. Natl. Acad. Sci. USA 1987, 84, 8961-8965. [CrossRef]

(C) 2020 by the authors. Licensee MDPI, Basel, Switzerland. This article is an open access article distributed under the terms and conditions of the Creative Commons Attribution (CC BY) license (http://creativecommons.org/licenses/by/4.0/). 